\title{
A Comparative Study of Some Larval Stages of Penaeus monodon and Penaeus merguiensis (Crustacea : Decapoda) from Indonesia
}

\author{
$\operatorname{AUTHOR}(\mathrm{S})$ : \\ Juwana, Sri; Romimohtarto, Kasijan
}

\section{CITATION:}

Juwana, Sri ...[et al]. A Comparative Study of Some Larval Stages of Penaeus monodon and Penaeus merguiensis (Crustacea : Decapoda) from Indonesia. PUBLICATIONS OF THE SETO MARINE BIOLOGICAL LABORATORY 1987, 32(1-3): 109-122

ISSUE DATE:

1987-08-10

URL:

http://hdl.handle.net/2433/176133

RIGHT: 


\title{
A Comparative Study of Some Larval Stages of Penaeus monodon and Penaeus merguiensis (Crustacea: Decapoda) from Indonesia
}

\author{
By \\ Sri Juwana and Kasijan Romimohtarto \\ Center for Oceanological Research and Development, Indonesian Institute \\ of Sciences, P.O. Box 580 DAK, Jakarta, Indonesia
}

With Text-figures $1-8$ and Tables 1-4

\begin{abstract}
The nauplius VI, protozoea II and mysis II of Penaeus monodon and P. merguiensis from Indonesian waters have been described and illustrated. The similarities and the differences between the two species have been observed. The comparison between the present study and that by previous authors have been made. Setation on endopod of maxilliped I and maxilliped II of protozoea and mysis stages as specific characters for identification is suggested.
\end{abstract}

Two species of economically important penaeid prawns, Penaeus merguiensis De Man, 1888, and, P. monodon Fabricius, 1798, are among the many penaeids found in Indonesian waters. Although it is well known that their larvae occur in the coastal waters and are often mixed together (Noor-Hamid, 1976), accurate identification of their wild larvae is now possible only for post-larvae and juveniles, and identification at earlier stages is not yet succeeded. Larval stages of these species have already been described by some authors based upon materials from India (Silas et al., 1978) and the Philippines (Motoh, 1979; Motoh \& Buri, 1979). Their information is available for identification of these larvae in Indonesian waters to certain extent, but some problems, which are probably related to difference of material and/or accuracy in observation, must be cleared before it is applied to Indonesian materials. In the present paper, larval stages of these two species, especially nauplius VI, protozoea II and mysis II, are described and compared on the basis of specimens reared in the laboratory, paying special attention to the type and number of setae on the appendages.

Larvae of two species of penaeid prawns, Penaeus monodon and $P$. merguiensis, reared from eggs spawned in the laboratory were received from the Brackishwater Aquaculture Development Centre, Jepara. The larvae were preserved in 10\% formalin and were used for morphological observation. Dissection of appendages was performed in 10\% glycerin and drawings were made with Projectina, a micro photographic and drawing instrument. For each larval stage of the two species, 10 specimens were randomly taken for measurements with a micrometer eyepiece. The identification of substages is based on that used by Motoh (1979).

Body lengths of nauplii were measured along the midline from apical to caudal margins, exclud-

Publ. Seto Mar. Biol. Lab., 32(1/3), 109-122, $1987 . \quad$ (Article 3) 
ing furcal spines. Body widths were measured across the greatest extent. Body lengths of zoea and mysis stages were measured along the mid-line from the anterior margin of the carapace (excluding rostrum) to the posterior margin of the telson. Carapace lengths were measured along the mid-line from anterior to posterior margin. Total lengths of zoea and mysis stages were measured along the mid-line from tip of rostrum to tip of telson (excluding spines).

To depict accurately the setation, the existence and the relative lengths of the setae on the appendages were checked thoroughly by examining all the specimens of each larval stage to ensure that no seta had been overlooked or wrongly drawn. Secondary setation of plumose spines and setae were generally not shown to avoid cluttering of the figures. All scales in the figures are $0.1 \mathrm{~mm}$.

\section{Results}

\section{Nauplius VI}

The characteristic features of this substage, common to both species, are the number of furcal setae which is $7+7$ and the presence of rudimental carapace which

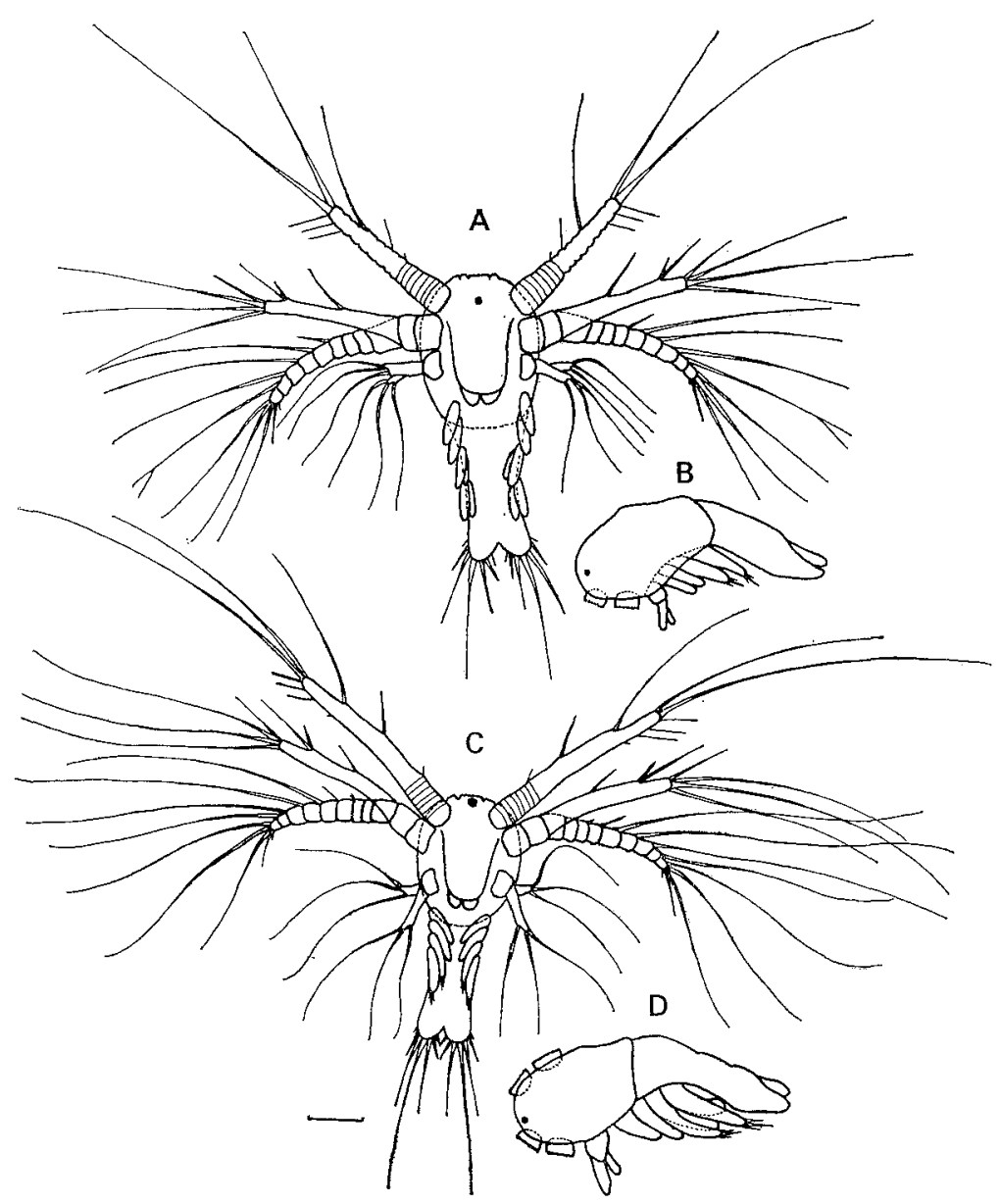

Fig. 1. Nauplius VI of Penaeus monodon. A, ventral view; B, lateral view. Nauplius VI of Penaeus merguiensis. C, ventral view; D, lateral view. 
Table 1. Comparison of morphological characters in nauplius VI of Penaeus monodon and $P$. merguiensis.

\begin{tabular}{lcc}
\hline \multicolumn{1}{c}{ Characters } & P. monodon & P. merguiensis \\
\hline Body length & $0.54-0.57 \mathrm{~mm}$ & $0.35-0.44 \mathrm{~mm}$ \\
Body width & $0.20 \mathrm{~mm}$ & $0.17-0.20 \mathrm{~mm}$ \\
Carapace length & $0.27-0.30 \mathrm{~mm}$ & $0.17-0.20 \mathrm{~mm}$ \\
Antennule length & $0.32-0.38 \mathrm{~mm}$ & $0.35-0.36 \mathrm{~mm}$ \\
Antennule form & $\begin{array}{l}\text { The proximal region large, gradually } \\
\text { decrease in size to tip } \\
\text { Surface region of distal half not } \\
\text { smooth, with many constriction }\end{array}$ & Almost similar from base to subapical \\
& & Surface region of distal half smooth \\
\hline
\end{tabular}

becomes distinct on the body surface. In several nauplii, frontal organs were discernible on the anterior margin. Mandible consists of non-segmented protopod, endopod and exopod. Endopod and exopod each with three plumose setae terminally. Rudiments of maxilla and maxilliped covering the major portion of the ventral part of the body, posterior to the labrum (Fig. 1). It is observed, however, that these rudiments of nauplius VI of Penaeus merguiensis is shorter than the counterpart in $P$. monodon (Table 1 ).

Antennule with seven or eight short indistinct basal segments. Two long plumose setae and one aesthetasc seta present terminally. Two aesthetasc setae on subapical outer margin. The three aesthetascs arranged into a row in which they are equally spaced. One long, one moderately long and one short plumose setae present on inner margin. One short simple seta arising from outer margin in $P$. merguiensis, no such seta in $P$. monodon. Other differences are as in Table 1.

Antenna consisting of two-segmented protopod, unsegmented endopod and nine-segmented exopod. Protopod without seta. Endopod bearing three long and one moderately long plumose setae terminally, and two moderately long and one shorter plumose setae laterally. Exopod with three long, one moderately long plumose setae and one very short simple seta terminally; fourth segment bearing one moderately long plumose seta on inner margin, fifth to eighth segments bearing one long plumose seta each. In several specimens of $P$. merguiensis, an additional very short seta exists on the inner margin of third segment of exopod. There is difference in antennal lengths of the two species. Antennal length of nauplius VI of $P$. monodon is greater, ranging from $0.34 \mathrm{~mm}$ to $0.38 \mathrm{~mm}$, than that of P. merguiensis, which ranges from $0.30 \mathrm{~mm}$ to $0.325 \mathrm{~mm}$.

\section{Protozoea II}

The characteristic features common to both species of this substage are the presence of a ventrally bent rostrum and a pair of bifurcate supraorbital spines, the appearance of stalked compound eyes, which are free from the carapace, and the segmentation of the abdomen (Fig. 2). A naupliar eye present. Six thoracic segments posterior to carapace almost similar to first five abdominal segments in size. Last abdominal segment elongate, with $7+7$ plumose setae on posterior prominences. 


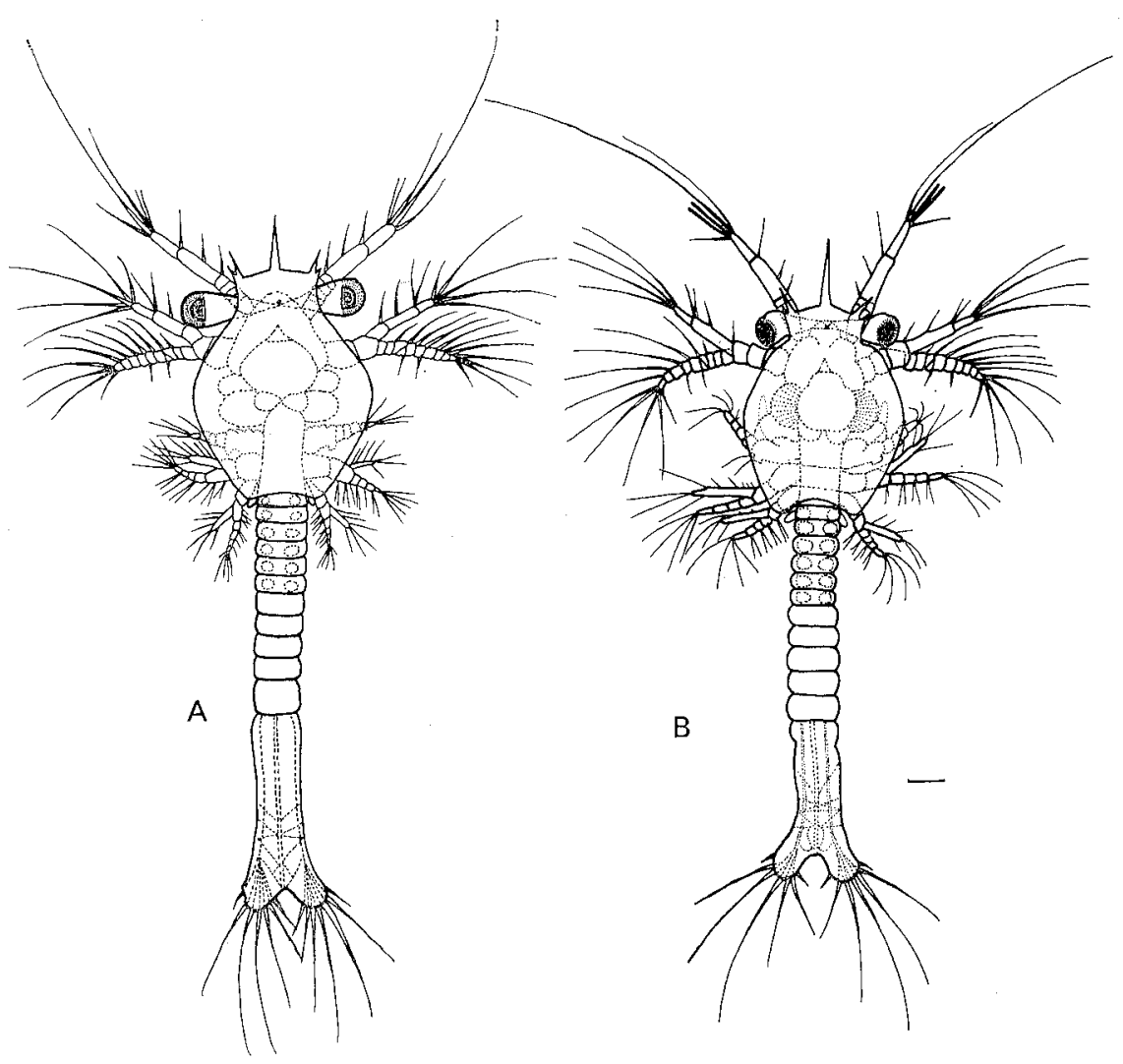

Fig. 2. Protozoea II of Penaeus monodon. A, dorsal view. Protozoea II of Penaeus merguiensis. $\mathrm{B}$, dorsal view.

Buds of the third maxilliped and five pairs of pereiopod are present.

Antennule (Figs 3A \& 4A) bears a peduncle of three major segments. Proximal part consisting of five short basal segments with one short plumose seta on inner margin. Middle part with one short plumose seta on inner margin. Another plumose seta, short in P. monodon and moderately long in P. merguiensis, is found distally on inner margin. This is the only one difference in setation between the two species. Distal part with two long plumose setae terminally; two aesthetasc setae and one moderately long plumose seta subterminally. Antennule length of both species is almost the same, $0.40-0.45 \mathrm{~mm}$ in $P$. monodon and $0.40 \mathrm{~mm}$ in P. merguiensis.

Antenna (Figs 3B \& 4B) consisting of protopod of two naked segments, threesegmented endopod and ten-segmented exopod. Endopod with four long and one short plumose setae terminally, two distal and one median short plumose setae laterally on mid-segment, and one distal short plumose seta laterally on proximal segment. Exopod has three long and one moderately long plumose setae terminally, one long plumose seta on each inner margin on segments V-IX, one short plumose seta on segment II and one moderately long plumose seta on segment III, both on inner margin; segments IV-VI bearing one short plumose setae on each outer margin. 


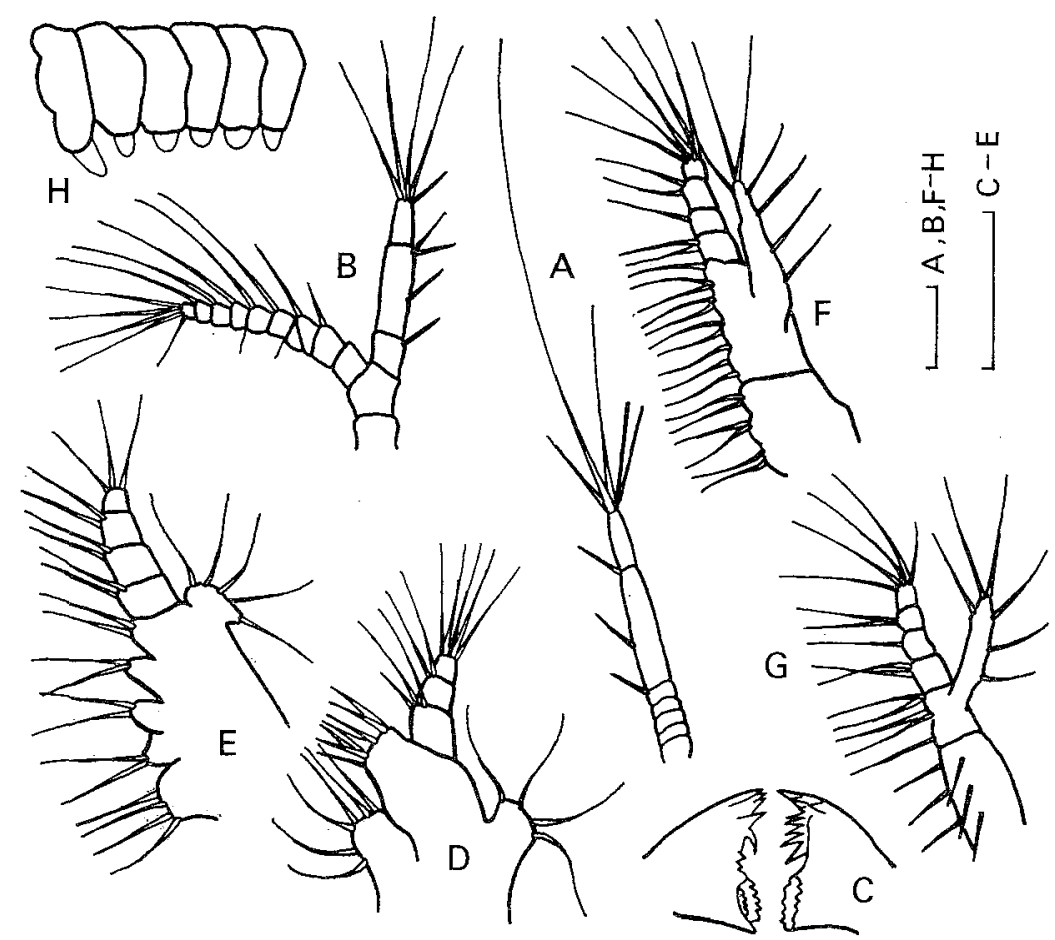

Fig. 3. Protozoea II of Penaeus monodon. A, antennule; B, antenna; C, mandible; D, maxillule; E, maxilla; F, first maxilliped; $G$, second maxilliped; $H$, third maxilliped.

Mandible consisting of unjointed protopod and carpus mandibulae. Right and left mandibles asymmetrical. Incisor part more developed than molar part in general. Right mandible armed with two standing teeth, left mandible with five standing teeth (Figs $3 \mathrm{C} \& 4 \mathrm{C}$ ).

Maxillule of both species has a similar form and the same setation on endopod and exopod (Figs 3D \& 4D). Endopod with three segments; proximal segment bearing two long and one short plumose setae; middle segment bearing two long plumose setae; distal segment bearing five long plumose setae terminally. Exopod small, spherical with four long plumose setae. Setation of protopod is different between two species; in $P$. monodon, proximal endite bears six plumose setae and distal endite bears seven cuspidate setae, while in $P$. merguiensis the same endites bear seven and six setae respectively.

Maxilla of both species has similar setation on endopod and exopod (Figs 3E \& 4E). Endopod with four segments, setation formula from proximal to distal segment $2+2+2+3$ long plumose setae. Exopod ovoid, with five long plumose setae. Setation on protopod is different between two species. In $P$. monodon the proximal segment bears $4-6$ plumose setae, while in $P$. merguiensis it bears ten $(7+$ 3) plumose setae.

First maxilliped of both species consisting of two-segmented protopod, four- 


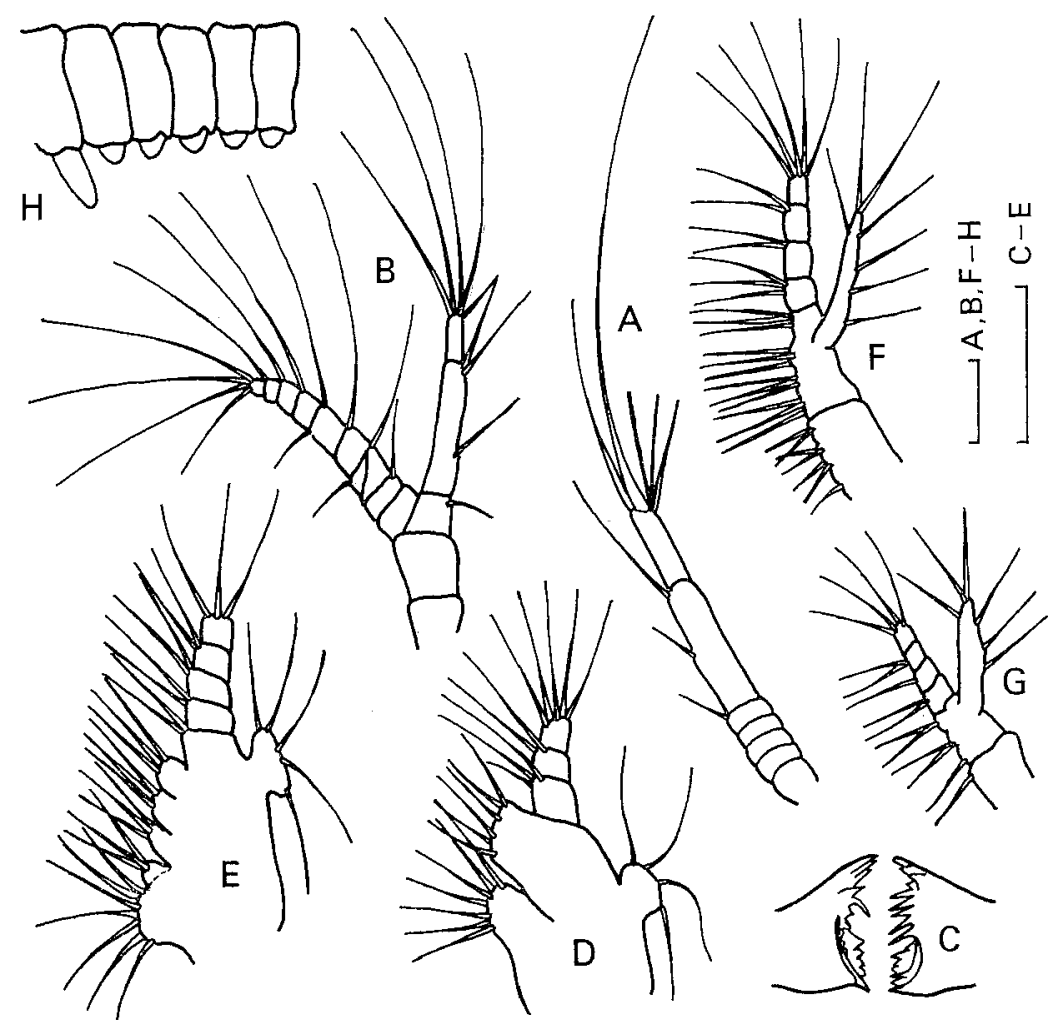

Fig. 4. Protozoea II of Penaeus merguiensis. A, antennule; B, antenna; C, mandible; D, maxillule; E, maxilla; F, first maxilliped; $G$, second maxilliped; $H$, third maxilliped.

segmented endopod, and unsegmented exopod (Figs 3F \& 4F). Exopod is not articulated with protopod, bearing on outer surface two long plumose setae terminally, two moderately long plumose setae subterminally and three moderately long plumose setae laterally. The setation on endopod and protopod is different between two species (Table 2). In $P$. monodon the proximal segment of endopod bears two plumose setae and the second segment bears one plumose seta, while in $P$. merguiensis the same segments bear three and two plumose setae, respectively.

Maxilliped II consisting of two-segmented protopod, four-segmented endopod and unsegmented exopod. The exopod not articulated with protopod, (Figs 3G \& 4G). It bears three plumose setae on outer margin, two terminally and one on inner margin. Setation on endopod and protopod is different between two species. As shown in Table 2, distal segment of endopod of $P$. monodon bears five $(4+1)$ plumose setae while that of $P$. merguiensis bears four plumose setae. The proximal segment of protopod of the former species bears six plumose setae and that of the latter species bears only one plumose seta.

\section{Mysis II}

The characteristic features of this substage, common to both species, are de- 
Table 2. Comparison of morphological characters in protozoea II of Penaeus monodon and $P$. merguiensis. p.s.: plumose seta.

\begin{tabular}{|c|c|c|}
\hline Characters & P. monodon & P. merguiensis \\
\hline Total length & $2.03-2.65 \mathrm{~mm}$ & $1.65-1.90 \mathrm{~mm}$ \\
\hline Body length & $1.30-2.30 \mathrm{~mm}$ & $1.50-1.70 \mathrm{~mm}$ \\
\hline Carapace length & $0.45-0.75 \mathrm{~mm}$ & $0.50-0.60 \mathrm{~mm}$ \\
\hline \multicolumn{3}{|l|}{ Maxilla protopod } \\
\hline proxima1 endite & 4-6 p.s. & $(7+3)$ p.s. \\
\hline second endite & 2-4 p.s. & 3 p.s. \\
\hline third endite & $2-4$ p.s. & 3 p.s. \\
\hline fourth endite & $2-4$ p.s. & 3 p.s. \\
\hline distal endite & 2-3 p.s. & 2 p.s. \\
\hline \multicolumn{3}{|l|}{ Maxilliped I } \\
\hline \multicolumn{3}{|l|}{ endopod } \\
\hline proximal segment & 2 p.s. & 3 p.s. \\
\hline second segment & 1 p.s. & 2 p.s. \\
\hline third segment & 2 p.s. & 2 p.s. \\
\hline distal segment & 5 p.s. & 5 p.s. \\
\hline \multicolumn{3}{|l|}{ protopod } \\
\hline proximal segment & 6 p.s. & 7 p.s. \\
\hline distal segment & 10 p.s. & 12 p.s. \\
\hline \multicolumn{3}{|l|}{ Maxilliped II } \\
\hline proximal segment & 2 p.s. & 2 p.s. \\
\hline second segment & 1 p.s. & I p.s. \\
\hline third segment & 2 p.s. & 2 p.s. \\
\hline distal segment & $(4+1)$ p.s. & 4 p.s. \\
\hline \multicolumn{3}{|l|}{ protopod } \\
\hline proximal segment & 6 p.s. & 1 p.s. \\
\hline distal segment & 5 p.s. & 5 p.s. \\
\hline
\end{tabular}

velopment of unsegmented pleopods and a spine on the antennal blade. Rostrum straight with no teeth. Supraorbital, pterygostomial and hepatic spines present. Each abdominal segment from fourth to sixth has dorsomedian spine, fifth and sixth segments with prominent posterolateral spines, sixth segment with additional prominent posterolateral spines. Curved ventromedian spine present ventrally to the junction of sixth abdominal segment with telson. Telson with $8+8$ spines, with cleft almost reaching to level of origin of penultimate pair of outer spines (Figs 5 \& 6).

In both species, antennule bears a stem of 3 segments. Distal segment bears two rami; proximal segment the longest, with a spine of stylocerite (Figs 7A \& 8A). There are several differences in the antennular features as listed in Table 3.

Antenna of both species consists of two-segmented protopod, one endopod and one exopod. Distal segment of protopod with one distolateral spine on outer margin. Endopod non-segmented with two short terminal setae. Exopod with a distolateral 


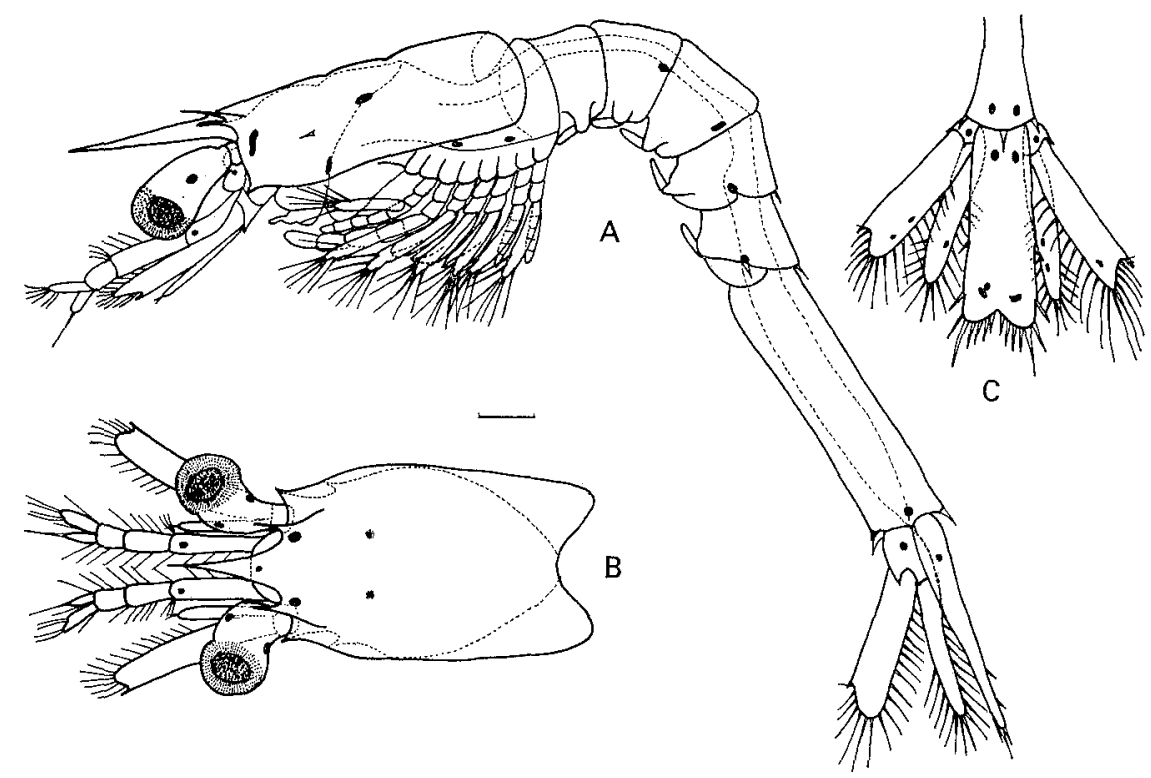

Fig. 5. Mysis II of Penaeus monodon. A, lateral view; B, carapace, dorsal view; C, telson, dorsal view.

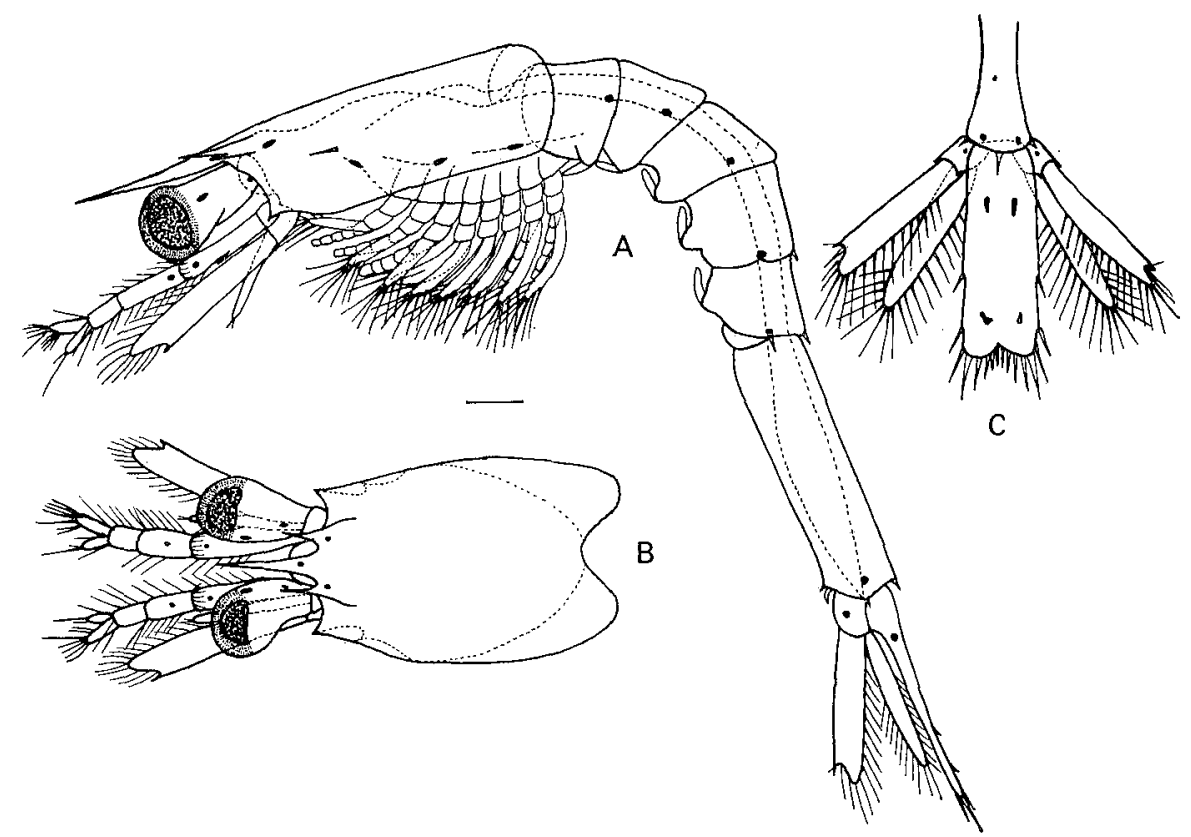

Fig. 6. Mysis II of Penaeus merguiensis. A, lateral view; B, carapace, dorsal view; $\mathrm{C}$, telson, dorsal view. 


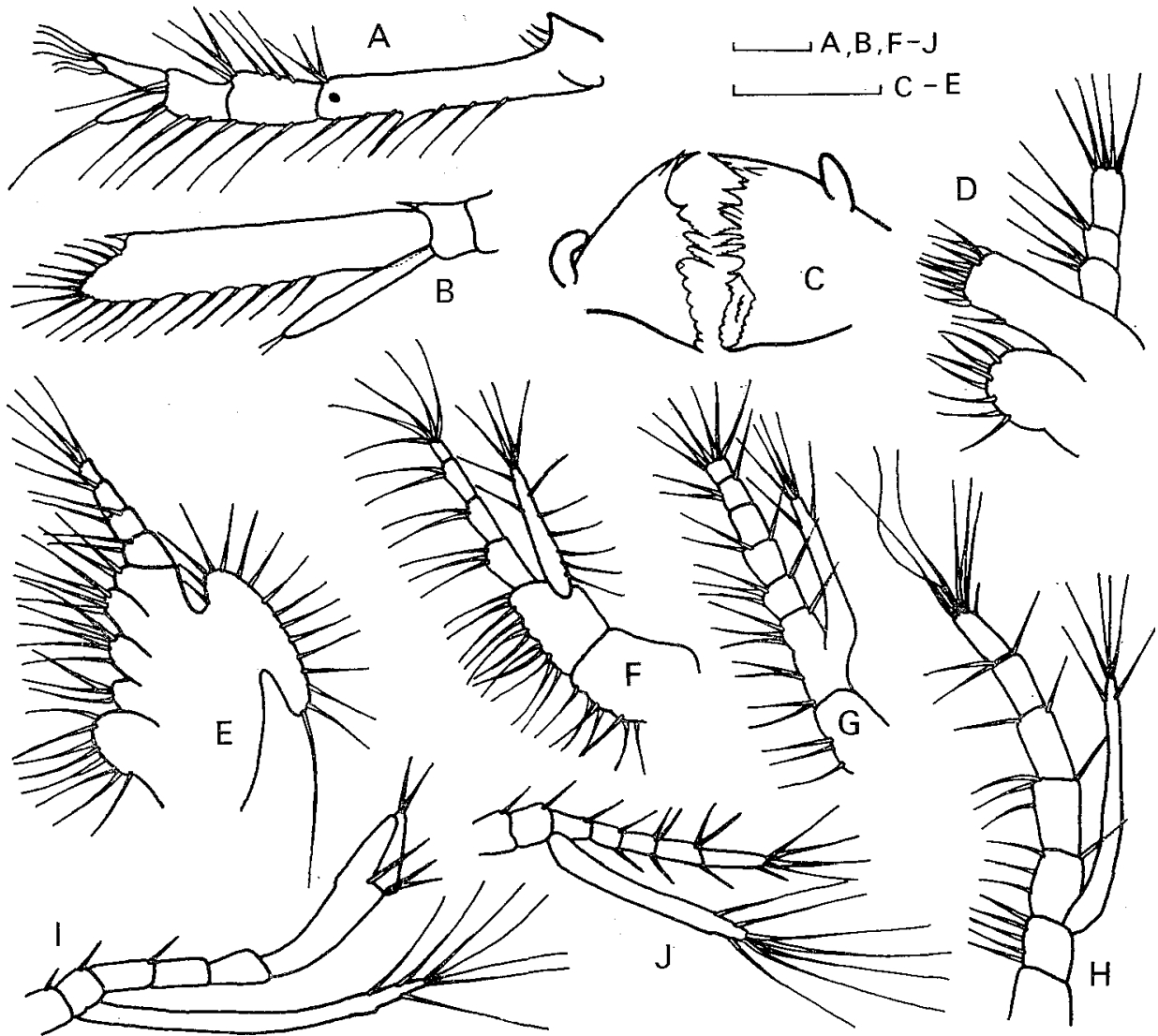

Fig. 7. Mysis II of Penaeus monodon. A, antennule; B, antenna; $\mathrm{C}$, mandible; D, maxillule; E, maxilla; F, first maxilliped; $G$, second maxilliped; $H$, third maxilliped; $I$, pereiopod $\mathrm{I}-\mathrm{III}$; J, pereiopod IV-V.

spine on outer margin and a number of setae on inner lateral and distal margins (Figs $7 \mathrm{~B} \& 8 \mathrm{~B}$ ). Antennal length ranges from $0.57 \mathrm{~mm}$ to $0.74 \mathrm{~mm}$ in $P$. monodon and from $0.60 \mathrm{~mm}$ to $0.68 \mathrm{~mm}$ in $P$. merguiensis. The number of plumose setae on exopod is 18 in P. monodon and 20 in P. merguiensis.

Mandible of both species has the same number of standing teeth; three in right and seven in left mandibles (Figs 9G \& 10C). Some teeth develop lateral spines. Mandibular palp represented by a small bud on dorsal surface of peduncle.

Maxillule of both species consists of three-segmented endopod and two protopod lobes with no exopod. Setation on endopod from proximal to distal is $3+2+5$ long plumose setae (Figs 7D \& 8D). Setation on the protopod in P. monodon is seven plumodenticulate setae and one plumose seta proximally, nine cuspidate setae and one simple seta distally; in P. merguiensis eight plumodenticulate setae and one plumose seta proximally, ten cuspidate setae and one simple seta distally (Table 3).

Setation on endopod and exopod of maxilla is the same in both species (Figs $7 \mathrm{E} \& 8 \mathrm{E}$ ). Endopod with four segments, setation formula from proximal to distal 


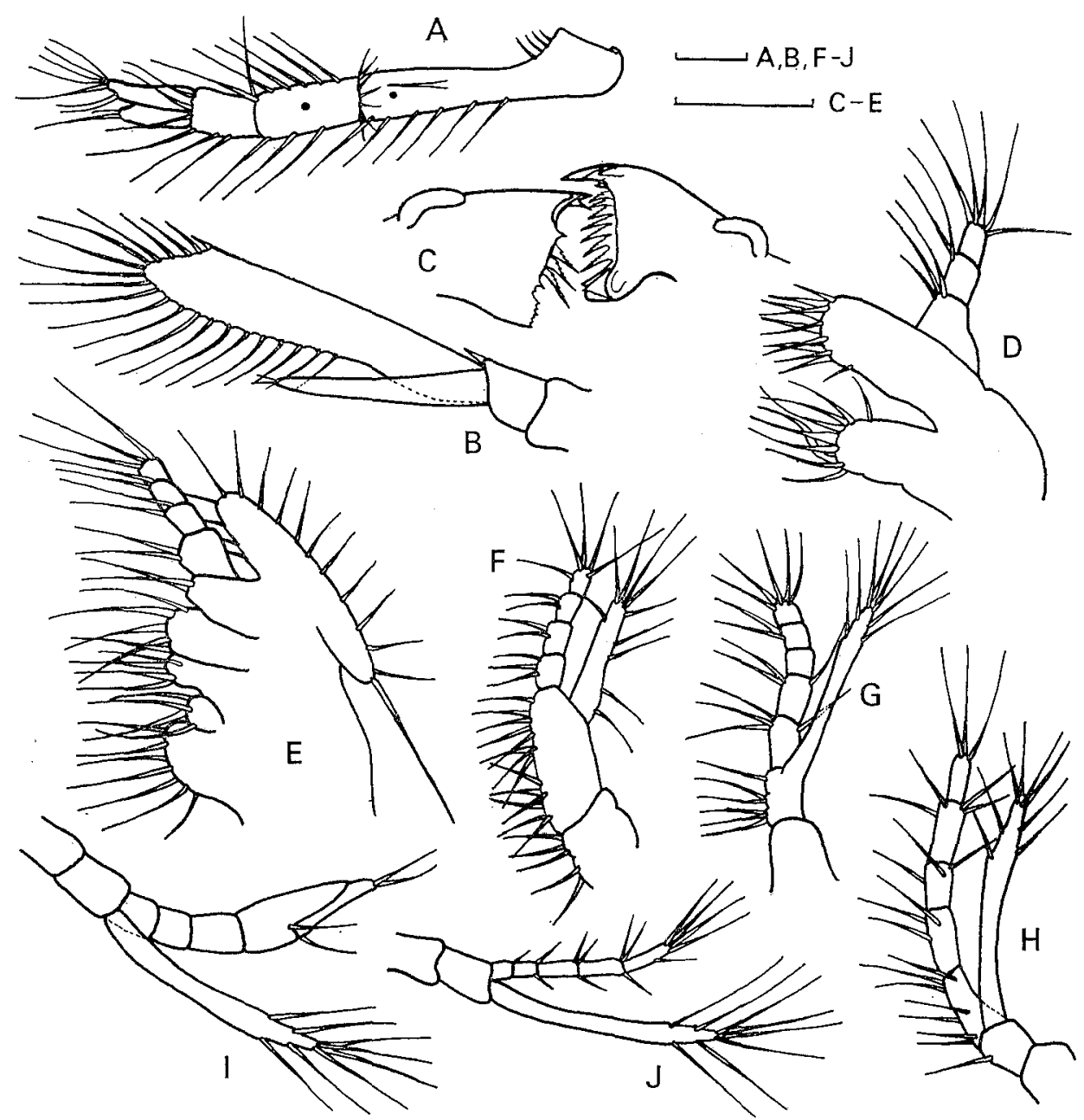

Fig. 8. Mysis II of Penaeus merguiensis. A, antennule; B, antenna; C, mandible; D, maxillule; E, maxilla; F, first maxilliped; G, second maxilliped; $H$, third maxilliped; I, pereiopod I-III; J, pereiopod IV-V.

is $2+2+2+3$ long plumose setae. Exopod armed with 16 long plumose setae along its inner margin, the most proximal much longer and stouter than the rest. The difference of maxilla between two species lies in the setation on protopod. In $P$. monodon the setation formula is $8+3+5+4+2$, while in $P$. merguiensis it is $7+4+$ $4+5+2$ (Table 3 ).

Maxilliped I of both species consists of four-segmented endopod, two-segmented protopod and unsegmented exopod (Figs $7 F$ \& 8F). Table 3 shows that the difference in setation between the two species lies in the numbers of setae on the protopod and exopod.

Maxilliped II of both species consists of two-segmented protopod, five-segmented endopod and unsegmented exopod (Figs 7G \& 8G). Setation is listed in Table 3. 
Table 3. Comparison of morphological characters in mysis II of Penaeus monodon and $P$. merguiensis.

Abbreviations: a.s., aesthetasc seta; c.s., cuspidate seta; p.s., plumose seta; pd.s., plumodenticulate seta; s.s., simple seta.

\begin{tabular}{|c|c|c|}
\hline Characters & P. monodon & P. merguiensis \\
\hline Total length & $3.70-4.15 \mathrm{~mm}$ & $3.90-3.95 \mathrm{~mm}$ \\
\hline Body length & $3.20-3.70 \mathrm{~mm}$ & $3.36-3.44 \mathrm{~mm}$ \\
\hline Carapace length & $0.66-0.92 \mathrm{~mm}$ & $0.76-0.92 \mathrm{~mm}$ \\
\hline Antennule length & $0.69-0.87 \mathrm{~mm}$ & $0.70-0.80 \mathrm{~mm}$ \\
\hline \multicolumn{3}{|l|}{ Antennule setation } \\
\hline \multicolumn{3}{|l|}{ proximal segment } \\
\hline inner margin & 6 long p.s. & 6 long p.s. \\
\hline outer margin & 3-4 short p.s. & 3-4 short p.s. \\
\hline distal margin & 3 short p.s. & 7-10 short p.s. \\
\hline \multicolumn{3}{|l|}{ mid-segment } \\
\hline inner margin & 3 long p.s. & 3 long p.s. \\
\hline outer margin & 3 long p.s. & 5 long p.s. \\
\hline distal margin & 3 long p.s. & 2 long p.s. \\
\hline \multicolumn{3}{|l|}{ distal segment } \\
\hline inner margin & 2 long p.s. & 3 long p.s. \\
\hline outer margin & - & - \\
\hline distal margin & 2 long p.s. & 3 long p.s. \\
\hline inner ramus & 1 long p.s. & $\begin{array}{l}1 \text { long p.s. + } \\
1 \text { short p.s. }\end{array}$ \\
\hline \multicolumn{3}{|l|}{ outer ramus } \\
\hline terminal & 4 a.s. & $\begin{array}{l}1 \text { long p.s. + } \\
4 \text { a.s. }\end{array}$ \\
\hline subterminal & 2 a.s. & 2 a.s. \\
\hline \multicolumn{3}{|c|}{ Maxillule protopod setation } \\
\hline proximal endite & 7 pd.s. + & 8 pd.s: + \\
\hline & 1 p.s. & 1 p.s. \\
\hline distal endite & 9 c.s. + & $10 \mathrm{c.s.}+$ \\
\hline & 1 s.s. & 1 s.s. \\
\hline \multicolumn{3}{|c|}{ Maxilla protopod setation } \\
\hline proximal endite & 8 p.s. & 7 p.s. \\
\hline second endite & 3 p.s. & 4 p.s. \\
\hline third endite & 5 p.s. & 4 p.s. \\
\hline fourth endite & 4 p.s. & 5 p.s. \\
\hline distal endite & 2 p.s. & 2 p.s. \\
\hline \multicolumn{3}{|l|}{ endopod } \\
\hline proximal segment & 3 p.s. & 3 p.s. \\
\hline second segment & 2 p.s. & 2 p.s. \\
\hline third segment & 2 p.s. & 2 p.s. \\
\hline distal segment & 5 p.s. & 5 p.s. \\
\hline \multicolumn{3}{|l|}{ protopod } \\
\hline proximal scgment & 7 p.s. & 5 p.s. \\
\hline distal segment & 11 p.s。 & 14 p.s. \\
\hline exopod & 12 p.s. & 10 p.s. \\
\hline
\end{tabular}


Table 3. Gontinued.

\begin{tabular}{|c|c|c|}
\hline Characters & P. monodon & P. merguiensis \\
\hline \multicolumn{3}{|l|}{$\begin{array}{l}\text { Maxilliped II setation } \\
\text { endopod }\end{array}$} \\
\hline proximal segment & 4 s.s. & 4 s.s. \\
\hline second segment & 3 s.s. & 3 s.s. \\
\hline third segment & none & none \\
\hline fourth segment & 3 s.s. & 2 s.s. \\
\hline distal segment & 6 p.s. & 5 p.s. \\
\hline \multicolumn{3}{|l|}{ protopod } \\
\hline proximal segment & 3 long p.s. & none \\
\hline distal segment & 8 long p.s. & 6 long p.s. \\
\hline exopod & $(1+4+1)$ long p.s. & $(2+4+2)$ long p.s. \\
\hline \multicolumn{3}{|l|}{$\begin{array}{l}\text { Maxilliped III setation } \\
\text { endopod }\end{array}$} \\
\hline proximal segment & 4 p.s. & 7 p.s. \\
\hline second segment & 4 p.s. & 3 p.s. \\
\hline third segment & 2 p.s. & 3 p.s. \\
\hline fourth segment & 3 p.s. & 4 p.s. \\
\hline distal segment & $(6+1)$ p.s. & 3 p.s. \\
\hline \multicolumn{3}{|l|}{ protopod } \\
\hline proximal segment & none & none \\
\hline distal segment & 5 p.s. & 1 p.s. \\
\hline exopod & $(1+4+1)$ p.s. & $(2+4+2)$ p.s. \\
\hline \multicolumn{3}{|l|}{$\begin{array}{l}\text { Pereiopods I-III setation } \\
\text { endopod }\end{array}$} \\
\hline proximal segment & 1 s.s. & none \\
\hline second segment & none & none \\
\hline third segment & none & none \\
\hline propodus & $1 \mathrm{s.s.}$ & 1 s.s. \\
\hline dactylus & $(2+2)$ s.s. & $(1+2)$ s.s. \\
\hline \multicolumn{3}{|l|}{ protopod } \\
\hline proximal segment & 1 s.s. & none \\
\hline distal segment & 1 s.s. & none \\
\hline exopod & $(1+4+2)$ p.s. & $(2+4+2)$ p.s. \\
\hline \multicolumn{3}{|c|}{$\begin{array}{l}\text { Pereiopods IV-V setation } \\
\text { endopod }\end{array}$} \\
\hline proximal segment & 1 s.s. & 1 s.s. \\
\hline second segment & 2 s.s. & 2 s.s. \\
\hline third segment & 3 s.s. & 3 s.s. \\
\hline fourth segment & 3 s.s. & 3 s.s. \\
\hline distal segment & $\begin{array}{l}4 \text { long p.s. }+ \\
1 \text { s.s. }\end{array}$ & $\begin{array}{l}4 \text { long p.s. }+ \\
1 \text { s.s. }\end{array}$ \\
\hline \multicolumn{3}{|l|}{ protopod } \\
\hline proximal segment & 1 s.s. & none \\
\hline distal segment & 1 s.s. & none \\
\hline exopod & $(1+4+2)$ long p.s. & $(2+4+2)$ long p.s. \\
\hline
\end{tabular}


Table 4. Ghromatophore pattern on mysis II of Penaeus monodon and P. merguiensis. + : present; - : absent.

\begin{tabular}{|c|c|c|c|c|}
\hline \multirow{2}{*}{ Location } & \multicolumn{2}{|c|}{$\begin{array}{l}\text { Chromatophore on } 2 \text { month- } \\
\text { preserved materials }\end{array}$} & \multicolumn{2}{|c|}{$\begin{array}{l}\text { Chromatophore on } 5 \text { month- } \\
\text { preserved materials }\end{array}$} \\
\hline & $P$. monodon & $P$. merguiensis & P. monodon & P. merguiensis \\
\hline \multicolumn{5}{|l|}{ Antennule } \\
\hline distal of proximal segment & + & + & - & - \\
\hline middle of mid-segment & - & + & - & - \\
\hline \multicolumn{5}{|l|}{ Eyes (dorsal view) } \\
\hline median & + & + & + & + \\
\hline lateral & + & + & + & - \\
\hline \multicolumn{5}{|l|}{ Carapace } \\
\hline basal of supraorbital spine & + & + & $\frac{1}{1}$ & + \\
\hline \multicolumn{5}{|l|}{ Cephalothorax } \\
\hline lateral face & + & - & + & - \\
\hline basal mandible & + & + & + & + \\
\hline basal maxilliped & + & + & + & + \\
\hline basal pereiopod & + & + & + & + \\
\hline \multicolumn{5}{|l|}{ Abdomen } \\
\hline posterolateral of segments II-VI & + & + & + & + \\
\hline \multicolumn{5}{|l|}{ Telson (dorsal view) } \\
\hline proximal & + & + & + & + \\
\hline distal & + & + & + & + \\
\hline \multicolumn{5}{|l|}{ Uropod } \\
\hline exopod median & + & - & - & - \\
\hline exopod basal & + & - & - & - \\
\hline endopod median & + & + & - & - \\
\hline
\end{tabular}

Maxilliped III of both species consists of two-segmented protopod and five-segmented endopod (Figs 7 H \& 8H). Exopod without segment. Setation is listed in Table 3.

Pereiopods I, II and III have a similar form in both species (Figs 7I \& 8I). Each consists of two-segmented protopod, five-segmented endopod and unsegmented exopod. The distal two segments of endopod forming rudimentary chelae. Segmentation of pereiopods IV and $V$ is the same as that of pereiopods I-III, except that the distal two segments of endopod do not form chelae (Figs. 7J \& 8J). Setation on pereiopods I-V is listed in Table 3.

The presence of chromatophores on antennule, eyes, carapace, cephalothorax, abdomen, telson and uropod was ascertained from the materials preserved for two months and five months (Table 4). The difference in the chromatophore pattern between $P$. monodon and $P$. merguiensis in two month-preserved material lies in the absence of the chromatophore on the middle of the mid-segment of antennule of $P$. monodon and on the posterolateral side of the first abdominal segment of this species. In P. merguiensis, chromatophores on the lateral face of cephalothorax and on 
the mediobasal segment of the exopod of uropod are absent. In five month-preserved materials, the chromatophores on antennule and uropod disappear.

\section{Discussion}

Motoh \& Buri (1979) compare the larval characters of 12 substages of three species, Penaeus merguiensis, $P$. monodon and P. japonicus, and note, among other characters, that the setation on endopod of maxilliped II of mysis II in P. merguiensis is $4+$ $3+0+2+5$ and $4+3+0+3+5 / 6$ in $P$. monodon, and that the dorso-median spine on the third abdominal segment is absent in $P$. merguiensis but present in $P$. monodon.

The present authors find that the setation formula for endopod of maxilliped II of mysis II in $P$. monodon is always $4+3+0+3+6$. The dorso-median spine on third abdominal segment is absent in $P$. monodon. This is contrary to the description of Motoh \& Buri (1979) and also to that of Silas et al. (1978). In addition, there is difference in the number of long plumose setae on inner margin to tooth of antenna, which is 18 in P. monodon and 20 in P. merguiensis.

Nauplius VI of $P$. monodon and $P$. merguiensis are so similar that discrimination between these species is impossible at present.

Motoh \& Buri (1978) do not find the difference between protozoea II of $P$. merguiensis and $P$. monodon while the present authors find the difference in the setation on endopod of both maxilliped I and II as follows: (1) setation on endopod of maxilliped I from proximal to distal segments of $P$. monodon is $2+1+2+5$ whereas that of $P$. merguiensis is $3+2+2+5$; (2) setation on endopod of maxilliped II from proximal to distal segments of $P$. monodon is $2+1+2+5$ and that of $P$. merguiensis is $2+1+2+4$.

\section{Acknowledgement}

The authors thank the Head of the Brackishwater Aquaculture Development Centre, Jepara, Indonesia, for providing some of the materials used in the study. They also thank Dr. S. Nishida of the Ocean Research Institute, University of Tokyo, for revising and correcting the manuscript.

\section{References}

Motoh, H. 1979. Larvae of decapod Crustacea of the Philippines-III. Larval development of the giant tiger prawn, Penaeus monodon, reared in the laboratory. Bull. Jap. Soc. Sci. Fish., 45: 12011216.

- _ \& P. Buri. 1979. Larvae of decapod Crustacea of the Philippines-IV. Larval development of the banana prawn, Penaeus merguiensis reared in the laboratory. Bull. Jap. Soc. Sci. Fish., 45: 1217-1235.

Silas, E.G., M.S. Muthu, N.N. Pillai, \& K.V. George. 1978. Larval development-Penaeus monodon Fabricius. CMFRI Bull., 28: 2-12.

Noor-Hamid, S. 1976. The occurrence and abundance of shrimp fry at Jepara in 1975 and 1976. Bull. Shrimp Culture Res. Centre, 2: 158-168. 